\title{
Novel Partial Esterification Reaction in Poly(amic acid) and Its Application for Positive-Tone Photosensitive Polyimide Precursor
}

\author{
By Masao TomiKaWA, ${ }^{*}$ Satoshi Yoshida, and Naoyo OKAMOTO
}

We found novel quantitative esterification in poly(amic acid) (PAA) by reacting with $N, N$-dimethylformamide dialkyl acetals (DFAs). Different alkyl ester was obtained by changing the alkyl group in DFAs. The esterification ratio was determined by amount of DFAs. The reaction proceeds under mild condition without any catalysis. It has not been reported such a kind of quantitative partial esterification before. The partial esterification allowed us to control the solubility of PAA to alkaline solutions. The strict solubility rate control to alkaline solution of PAA was quite important for positive tone photosensitive polyimide (posi PSPI). The partial esterification of PAA gave us a way to strict dissolution control. By using it, we could obtain posi PSPI just mixing with diazonaphthoquinone compound.

KEY WORDS: Dimethylformamide-Dialkyl Acetals / Esterified Poly(amic acid) / Partial Esterification / Photosensitive Polyimide /

Diazonaphthoquinone Compound /

Polyimides are widely used for semiconductor applications such as inter-layer dielectrics, protection layers (buffer coatings), and re-distribution layers for wafer level package. ${ }^{1}$ For these applications, polyimide is required to make a fine pattern by photo-lithographic technique. In early times polyimide was patterned by chemical etching through photo-resist pattern. In order to simplify the polyimide pattering process, several groups developed the addition of photosensitivity to polyimide precursor namely PSPI. ${ }^{2,3}$ Most of the PSPIs were negative tone type, which made exposed area insoluble by photoreaction. In order to progress semiconductor, polyimide is required fine pattern such as $5 \mu \mathrm{m}$ or less. To realize such a fine pattern, posi PSPI was desired. First posi PSPI was reported by Loprest et $a{ }^{4}{ }^{4}$ The posi PSPI was composed of PAA and naphthoquinone diazide compound which is popular for novolak photo resist system. But it was not realized due to high solubility of PAA to alkaline solution. In order to obtain suitable solubility of PAA, Simmons reported partial protection by reaction with 1,4-dihydropyrane. ${ }^{5}$ There were few drawbacks for this reaction. One was that the reaction did not proceed quantitatively. Another was that reaction condition needs acidic catalyst. Excess amount of 1,4-dihydropyrane with acidic catalyst and long reaction time were required. Posi PSPI from special PAA structure was reported by Sakayori et al. ${ }^{6}$

On the other hand, Rubner reported positive tone photosensitive polybenzoxazole precursor. ${ }^{7}$ Polybenzoxazole precursor was poly(hydroxyamide) which has phenolic groups in the polymer chain. The acidity of phenol group was much weaker than that of aromatic carboxylic acid. The positive tone photosensitive polybenzoxazole precursor was applied for buffer coating of semiconductor devices. ${ }^{8}$ Recently Watanabe et al. reported the negative tone photosensitive polybenzoxazole precursor by using acid catalysis cross linking. ${ }^{9}$
From the point of polyimide base development, Kubota reported a different posi PSPI by introduction of o-nitirobenzyl group to carboxylic acid in PAA. ${ }^{10}$ Omote reported chemical amplification system by mixing with t-butyl protected PAA and photo-acid-generators. ${ }^{11}$ Okabe invented the posiPSPI by mixing with phenolic group containing poly(amic ester) and dinaphthoquinone diazide to reduce the dissolution of polyimide precursor. ${ }^{12}$ Those posi PSPIs, however, were difficult to synthesize. Therefore simple PAA base posi PSPI was desired. Tamura et al. developed an image-reversed technique by using negative ionic bonded PSPI. ${ }^{13}$ The technique utilized the glass transition temperature $\left(T_{\mathrm{g}}\right)$ difference between exposed area and unexposed area. However this technique required very strict control of post exposure baking temperature.

Oyama et al. reported to obtain various types of posi PSPI by new reaction method. ${ }^{14}$ This patterning process required to use strong base and organic solvent. Those PSPIs progress was summarized by Fukukawa and Ueda. ${ }^{15}$

In order to obtain posi PSPI which could be patterned in the wide process window, it was important to control the dissolution rate of PAA to the alkaline solution. In this article, we reported finding of novel partial quantitative esterification of PAA and the dissolution rate control to the alkaline solution. In addition, we prepared the posi PSPI by using the quantitative esterified PAA. This method was easy to obtain various types of posi PSPI.

\section{EXPERIMENTAL}

\section{Materials}

4,4'-Diaminodiphenylether(oxy-dianiline, ODA) was obtained from Wakayama-Seika. 3,3',4,4'-Diphenylether tetracarboxylic acid dianhydride (ODPA) was obtained from 
Manac. 3-Amino phenol (AMP) was purchased from TokyoKasei. DMF dialkyl acetals (DFAs) were purchased from Tokyo-Kasei. $N$-methyl-2-pyrolidone (NMP) and $\gamma$-butylolactone (GBL) were obtained from Mitsubishi-Chemical. Diazonaphthoquinone compound (DNQ) was purchased from Toyo Gosei. Tetramethyl ammonium hydroxide (TMAH) solution was obtained from Mitsubishi Gas Chemical. Other chemicals were purchased from Tokyo-Kasei. All the chemicals were used without any treatment.

Synthesis of $\boldsymbol{N}$-Phenylphthalamic Acid (1). Phthalic anhydride $(14.80 \mathrm{~g}, 100 \mathrm{mmol})$ was added to aniline $(9.30 \mathrm{~g}$, $100 \mathrm{mmol}$ ) with $50 \mathrm{~mL}$ of NMP and stirred vigorously at room temperature under nitrogen flow for $4 \mathrm{~h}$. The solution was poured into $500 \mathrm{~mL}$ of water. The white precipitate was collected by filtration. The precipitate was washed by water several times. The washed precipitate was dried under vacuo at $50{ }^{\circ} \mathrm{C}$ for $72 \mathrm{~h}$. The yield was $19.63 \mathrm{~g}(85 \%)$. m.p. $170-172{ }^{\circ} \mathrm{C}$ (lit. $169-172{ }^{\circ} \mathrm{C}, 172^{\circ} \mathrm{C}^{16,17}$ ).

Esterification of 1 by Dimethylformamide Diethyl Acetal (DMFDEA). $\quad N$-Phenylphthalamic acid (1) $(2.41 \mathrm{~g}, 10 \mathrm{mmol})$ was dissolved into $10 \mathrm{~mL}$ of NMP. DMFDEA $(1.47 \mathrm{~g}$, $10 \mathrm{mmol}$ ) was added to the solution with $2 \mathrm{~mL}$ of NMP and stirred vigorously under fixed conditions. Reaction compounds ratio was determined by HPLC method. (Shimadzu LC-10, flow rate: $0.5 \mathrm{~mL} / \mathrm{min}$, Detector: SPD-10A $(254 \mathrm{~nm}$, Shimadzu), Column: Shim-Pack VP-ODS $(150 \mathrm{~mm} \times 4.6 \mathrm{~mm})$ (Shimadzu), Eluent; $\mathrm{CH}_{3} \mathrm{CN}, 0.1 \mathrm{M} \mathrm{H}_{3} \mathrm{PO}_{4}$ 9:1 (in volume)) Synthesis of Partial Esterified PAA by DFAs. ODA (18.02 g, $90 \mathrm{mmol}$ ) was dissolved into $100 \mathrm{~mL}$ of $\mathrm{NMP}$ at room temperature under nitrogen flow. ODPA $(31.01 \mathrm{~g}, 100 \mathrm{mmol})$ was added to the solution at one time with $40 \mathrm{~mL}$ of NMP. The solution was stirred vigorously at room temperature for $2 \mathrm{~h}$. Then AMP (3.18 g, $20 \mathrm{mmol})$ was added to the solution. Then the solution was heated to $40{ }^{\circ} \mathrm{C}$ and stirred for $4 \mathrm{~h}$.

Equivalent mole amount of DFAs to carboxylic acid in PAA were added to the PAA solution with $10 \mathrm{~mL}$ of NMP gradually. Then the solution was stirred under $50{ }^{\circ} \mathrm{C}$ for $2 \mathrm{~h}$. After the reaction, the solution was poured into $2 \mathrm{~L}$ of water. The precipitate was collected by filtration. The precipitate was washed by water several times. The washed precipitate was dried under vacuo at $80^{\circ} \mathrm{C}$ for $72 \mathrm{~h}$.

Molecular weight of the polymer was measured by Model1510 GPC (Waters). (Column TSK-GEL $\alpha 2500$, TSKGEL $\alpha 4000$ (Toso), Column temperature: $40^{\circ} \mathrm{C}$, Eluent: NMP containing $0.05 \mathrm{M} \mathrm{LiCl}$ and $0.05 \mathrm{M} \mathrm{H}_{3} \mathrm{PO}_{4}$. Flow rate $0.4 \mathrm{~mL} /$ min) Standard mono disperse polystylene (Toso) was used as molecular weight calibration.

\section{Measurement of Esterification}

Esterification ratio was determined from titration method by using 702SM Titrino (Metrohm) with $1 N$-tetra-butyl-ammonium hydroxide in methanol.

\section{Measurement of Dissolution Rate}

The esterifed PAA to be measured was dissolved into GBL at $20 \%$. The solution was filtered by $0.45 \mu \mathrm{m}$ pore-size

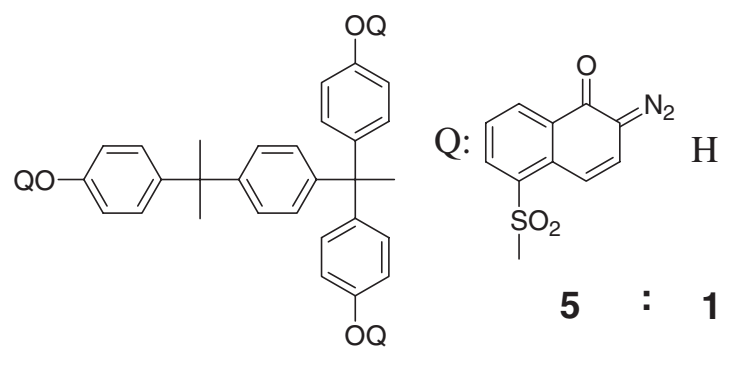

Figure 1. Chemical structure of naphthoquinone diazide compound (DNQ).

poly(tetrafluoroethylene) filter (Milipore). The filtrate solution was coated on 6 inch Silicone wafer (Shin-Etsu-Chemical) by spin coating and baked at $120^{\circ} \mathrm{C}$ for 3 min using by Tokyo Electron Mark-7. The coated thickness was about $2 \mu \mathrm{m}$ after the $120^{\circ} \mathrm{C}$ baking. The coated thickness was measured by STM-602 (Dainippon Screen) with material refractive index 1.64. The coated wafer was placed in dissolution rate monitoring apparatus (RDA-760, Lithotech Japan). The film thickness change in $2.38 \%$ TMAH solution was measured in situ by using the apparatus.

\section{Formulation of Positive PSPI}

Partial esterified PAA (10.0 g), DNQ (2.0 g) shown in Figure 1 and $N$-phenyl-3-aminopropyl trimethoxy silane $(0.2 \mathrm{~g}$, KBM-573, Shin-Etsu Silicones) were dissolved into $30 \mathrm{~mL}$ of GBL at room temperature. The solution was filtered by $0.45 \mu \mathrm{m}$ pore-size poly(tetrafluoroethylene) filter.

\section{Patterning of Positive PSPI}

The filtered sample was coated on 6 inch Silicone wafer about $3 \mu \mathrm{m}$ thickness after $120^{\circ} \mathrm{C}$ for 3 min soft-baking by spincoating method (Mark-7). The coated wafer was soft-baked by a hot plate at $120^{\circ} \mathrm{C}$ for $3 \mathrm{~min}$ using by Mark-7. Coated thickness was measured by STM-602. The baked wafer was exposed through a patterned mask by i-line stepper (GCA DSW-8750, exposure wave length: $365 \mathrm{~nm}$ ) with a $100 \mathrm{~mJ} / \mathrm{cm}^{2}$ to $1000 \mathrm{~mJ} / \mathrm{cm}^{2}$. The exposed wafer was developed with $2.38 \%$ TMAH solution by a puddle development (Mark-7) for $1 \mathrm{~min}$. The obtained pattern thickness was measured by STM-602. Cross sectional photos were obtained by a Scanning Electron Microscopy (SEM, Hitachi S-4800). The developed wafer was heated to $320^{\circ} \mathrm{C}$ for $1 \mathrm{~h}$ under nitrogen flow to convert patterned polyimide film (Koyo-thermo System INH-9).

\section{RESULTS AND DISCUSSION}

\section{Esterification of 1}

DFAs were prepared by Meerwein et al. ${ }^{18}$ Those reagents were developed for use of alkylating agent which converted lower molecular carboxylic acid into ester without any catalysis. ${ }^{19}$ Especially dimthylformamide dimethyl acetal and DMFDEA were known as esterification reagent for GCpretreatment. ${ }^{20}$ However, no one has not applied the reagents for esterification of carboxylic acid in polymer side branch. 
Table I. Reaction results of Model compound

\begin{tabular}{cccc}
\hline & $\begin{array}{c}\text { Starting } \\
\text { Material }\end{array}$ & $\begin{array}{c}\text { Ester } \\
\text { Compound }\end{array}$ & $\begin{array}{c}\text { Imide } \\
\text { Compound }\end{array}$ \\
\hline $\begin{array}{c}\text { Before } \\
\text { Reaction } \\
50^{\circ} \mathrm{C} \text { for } \\
2 \mathrm{~h}\end{array}$ & 100 & 0 & 0 \\
$80^{\circ} \mathrm{C}$ for \\
$\begin{array}{l}15 \mathrm{~min} \\
80^{\circ} \mathrm{C} \text { for } \\
2 \mathrm{~h}\end{array}$ & 5 & 88 & 10 \\
\hline
\end{tabular}

$\%$ by HPLC area at $254 \mathrm{~nm}$ absorption.
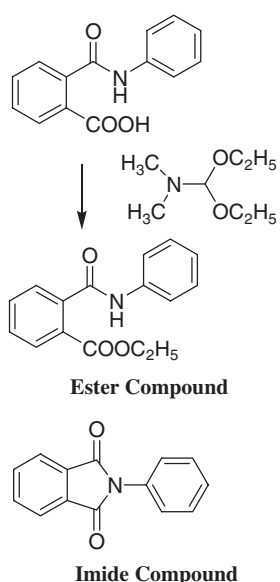

Imide Compound

Esterification of $\mathbf{1}$ by use of DMFDEA was investigated as a model reaction of PAA. The results were summarized in Table I. From our experimental data, $50{ }^{\circ} \mathrm{C}$ for $2 \mathrm{~h}$ was suitable reaction condition. Esterification reaction proceeded smoothly. As shown in table, reaction at higher temperature gave lower selectivity of esterification from imidizaiton. The selectivity from imidization was quite important to suppress UV absorption of polyimide precursor. From the result of the low molecular model reaction, the esterification method seemed to be meaningful to apply the esterification of PAA.

\section{Esterification of PAA}

Partial esterification of PAA was known as very difficult due to its competition with imidization reaction. To obtain partial esterified PAA, Simmons reported partial protection by reaction with excess amount of 1,4-dihydropyrane and acidic catalyst at $85^{\circ} \mathrm{C}$ for $6 \mathrm{~h} .{ }^{5} \mathrm{Yu}$ reported the partial esterified PAA by using ethyl-iodide and potassium carbonate. ${ }^{21}$ However those reactions were difficult to apply for practical use because of low yield and need for alkali metal and halogenated compounds. Choi obtained partial esterified PAA by using glycidyl methacrylate with a presence of triethylamine. ${ }^{22}$ This reaction conversion was less than 50\% from their results. In addition, the imidization was faster than esterification in those studies.

The esterification reaction scheme by using DMFDEA was shown in Figure 2. Esterification was done after polymerization continuously. The number average molecular weight of the PAA in this work was about 9000 by GPC. Esterification occurred in the case of PAA with good yield also. The reaction revealed high selectivity from imidization also. As shown in Figure 3, the reaction proceeded in proportion with DMFDEA amount. As much as we knew, this was first case to control the esterification ratio of PAA just by changing amount of reaction agent. The esterification reaction we found was quite unique from the point of polymer reaction and useful for convenient partial esterification of PAA.

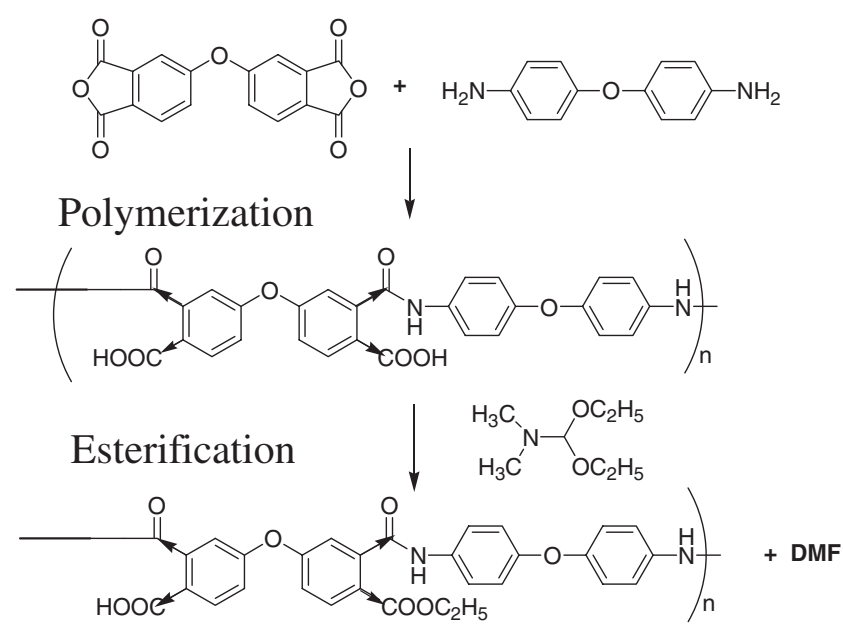

Figure 2. Reaction scheme of this work.

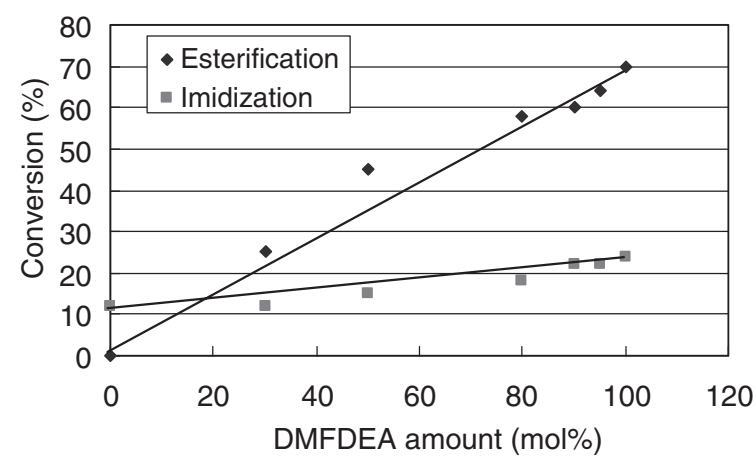

Figure 3. DMFDEA amount dependency on esterification and imidization.

Table II. Effect of alkyl groups of DFAs in PAA

\begin{tabular}{cccc}
\hline Alkyl group & Esterification & Imidization & $\begin{array}{c}\text { Ester/Imide } \\
\text { ratio }\end{array}$ \\
\hline Methyl & $65 \%$ & $30 \%$ & 2.2 \\
Ethyl & $70 \%$ & $25 \%$ & 3.0 \\
iso-Propyl & $60 \%$ & $10 \%$ & 6.0 \\
None* & $0 \%$ & $10 \%$ & - \\
\hline
\end{tabular}

Reaction condition: $50^{\circ} \mathrm{C} 2 \mathrm{~h} .{ }^{*}$ : No reaction with DFAs.

\section{Effect of Alkyl Groups in DFAs}

In previous section, we found that DMFDEA was effective for PAA esterification. To understand the effect of alkyl groups in DFAs, esterifications using by various DFAs were investigated. Those results were summarized in Table II. In the Table, "none" means that we did not react anything with PAA. As shown in the table, acetals with larger alkyl groups gave lower conversion. On the other hand, larger alkyl containing acetals showed higher esterification selectivity from imidization. Larger alkyl group interfered with imidization due to steric hinderance. Including the imidization and esterification, methyl or ethyl acetals converted carboxylic acid of PAA almost completely. 
Table III. Effect of reaction temperature on esterification

\begin{tabular}{ccc}
\hline $\begin{array}{c}\text { Reaction } \\
\text { Temperature } \\
\left({ }^{\circ} \mathrm{C}\right)\end{array}$ & $\begin{array}{c}\text { Esterification } \\
(\%)\end{array}$ & $\begin{array}{c}\text { Imidization } \\
(\%)\end{array}$ \\
\hline 30 & 50 & 8 \\
40 & 71 & 10 \\
50 & 70 & 15 \\
60 & 50 & 33 \\
70 & 53 & 52 \\
\hline
\end{tabular}

DMFDEA amount: Equivalent to carboxylic acid in PAA. Esterification and Imidization were determined by titration and FT-IR respectively.

\section{Effect of Reaction Condition}

The reaction mechanism of alkylation by DFA was thought to be generation of an oxo-stabilized carbenium ion. ${ }^{19} \mathrm{We}$ thought that the success of PAA esterification by DFA is following reason. Strong basicity of DFA due to existence of aliphatic amine group allowed forming ion pair with carboxylic group of PAA and DFA. The complex formation made the esterification effectively. After completion of the reaction, DFA was changed to DMF which is very weak base and good solvent of PAA. The change of basicity of DFA was thought to be important for suppressing imidization.

We investigated the reaction condition of the esterification summarized in Table III. The higher temperature condition gave higher imidization ratio. As expressed in previous section, higher imidization was not preferable due to UV absorption of PAA. It was concluded that $40-50{ }^{\circ} \mathrm{C}$ was suitable temperature for the reaction to obtain high selectivity from imidization. The esterification reaction could be done after polymerization consequently.

The quantitative partial esterification might be applied for not only PAA but poly(acrylic acid) or other carboxyl-group branch polymers. Reasons for usefulness of the esterification we found were as follows: The reaction did not need catalyst. The reaction proceeded under mild condition. In addition, byproduct arising from the reaction was DMF which was good solvent for most of polymers. And the most important thing was that we could control the esterification ratio by changing the amount of DFA.

\section{Posi PSPI from the Partial Esterified PAA}

The use of the esterification of PAA made us easily control the carboxylic concentration in PAA. The nature of controlling carboxylic group made us to obtain alkaline solubility control in polyimide precursor. Strict control of solubility to alkaline solution is one of most important factor for positive photosensitive materials using DNQ compound.

In semiconductor industries, $2.38 \%$ THAM solution was standard alkaline developer. We tried to control the posi PSPI $2.38 \%$ TMAH developable. Basically most of PAAs showed very high dissolution rate to $2.38 \%$ TMAH solution due to those high concentrations of carboxylic acid groups. The high dissolution rate of PAA made difficult to obtain polyimide based positive photosensitive materials. The quantitative esterification we found would realize to control the dissolution rate of polyimide precursor to optimal value. In most case, optimal dissolution rate was 40 to $1000 \mathrm{~nm} / \mathrm{min}$ by Kato et al. ${ }^{23}$

In order to obtain suitably dissoluble polyimide precursor, we measured the esterification ratio and dissolution rate of various partial esterified PAA. Those results were summarized in Figure 4. As shown in the Figure, we were able to control the dissolution rate of polyimide precursor by amount of DMFDEA. From the Figure, desired range of dissolution rate is achived in the range of between 90 to $95 \mathrm{~mol} \%$ of DMFDEA to carboxylic acid group in PAA.

Posi PSPI was prepared from the quantitative esterified PAA and DNQ shown in Figure 1. To obtain suitable dissolution rate to $2.38 \%$ TMAH solution, $93 \mathrm{~mol} \%$ of DMFDEA amount to carboxylic acid in PAA $\left(M_{\mathrm{n}}=9000\right)$ was chosen from Figure 4.

The posi PSPI was coated by spin coating method on Si wafer and baking on hot plate at $120^{\circ} \mathrm{C}$ for $3 \mathrm{~min}$. The softbaked PSPI was exposed by UV with high pressure $\mathrm{Hg}$ lamp $(365 \mathrm{~nm})$. The exposed PSPI was developed by $2.38 \% \mathrm{TMAH}$ solution and heated to $320^{\circ} \mathrm{C}$ for $1 \mathrm{~h}$. As shown in Figure 5, we obtained good pattern shape. By using our quantitative partial esterified PAA, we were able to obtain various kinds of posi PSPI. This process was quite unique and useful for PSPI development. In addition, various types of posi PSPI for different alkaline developer was able to be designed just by changing the amount of DFA.

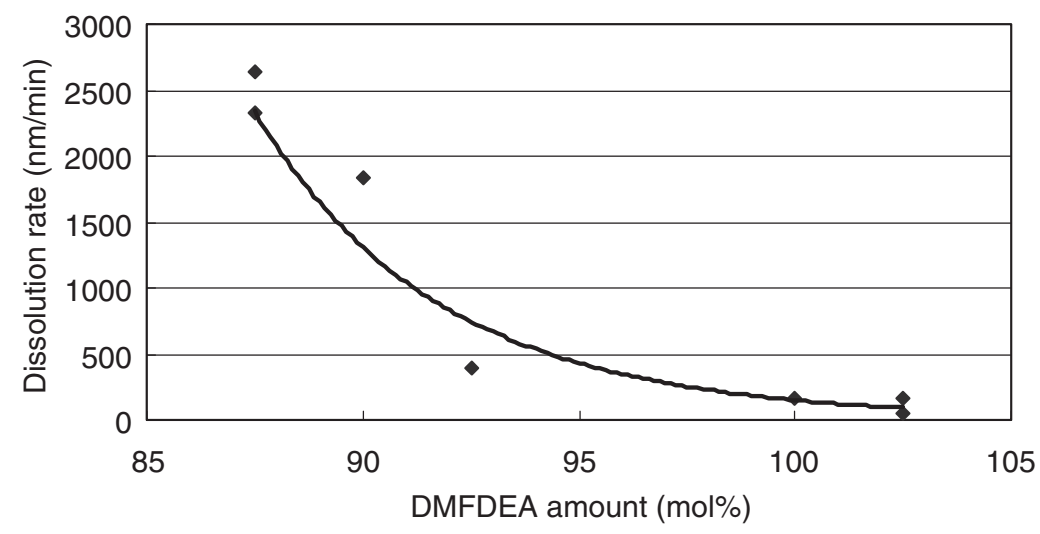

Figure 4. DMFDEA amount depecdency on dissolution rate of PAA to $2.38 \%$ TMAH solution. 


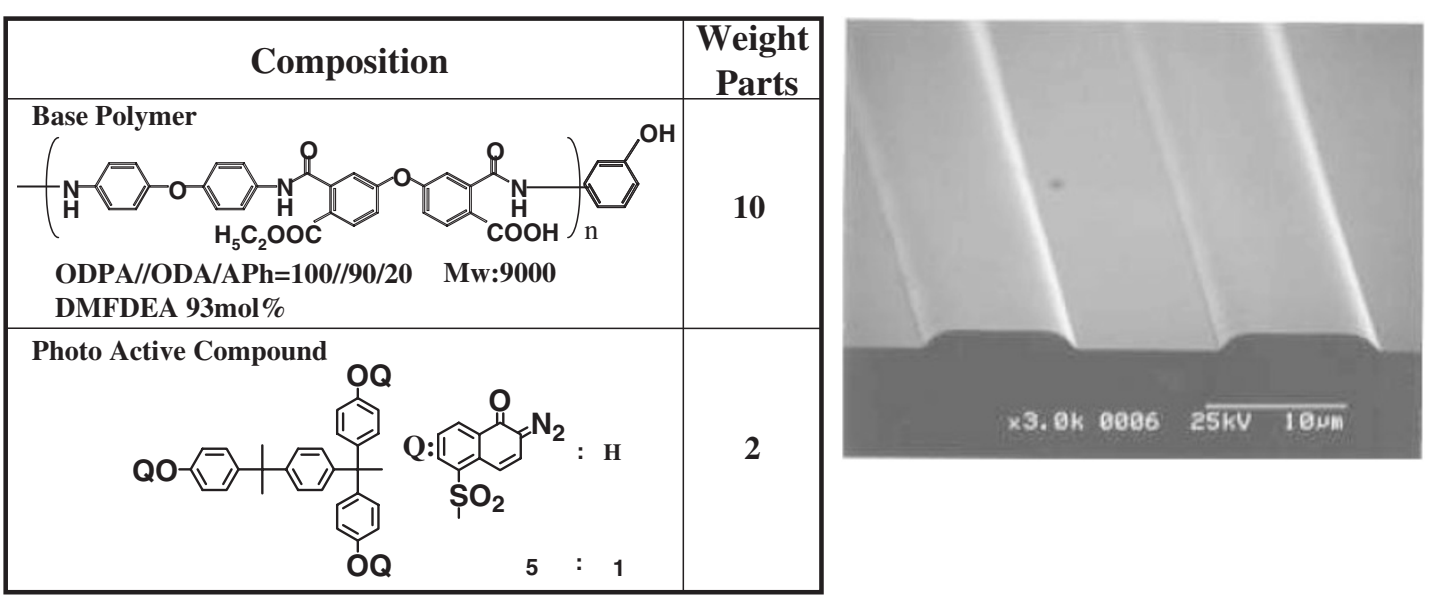

Figure 5. Composition of obtained positive photosensitive polyimide and patterning photo by scanning electron microscope (10 $\mu \mathrm{m}$ line and space).

\section{CONCLUSIONS}

We developed novel convenient partial esterification reaction for PAA by using DFAs. The reaction proceeds quantitatively under mild condition without any catalyst. Esterification ratio of PAA was determined by amount of DFA. The partial esterification allowed us to control a dissolution rate of partially esterified PAA to alkali solution precisely.

Novel posi PSPI was prepared by mixing the partially esterified PAA and DNQ successfully. The posi PSPI obtained in this work was easy to prepare. The reaction we found was quite useful for a base resin of posi PSPI.

Received: December 26, 2008 Accepted: April 24, 2009 Published: June 10, 2009

\section{REFERENCES}

1. M. Tomikawa, M. Suwa, S. Yoshida, Y. Fujita, R. Okuda, and G. Ohbayashi, J. Photopolym. Sci. Technol., 13, 357 (2000).

2. R. Rubner, H. Ahne, E. Kuhn, and G. Koloddieg, Photogr. Sci. Eng., 23, 303 (1979).

3. N. Yoda, H. Hiramoto, and M. Eguchi, Macromol. Rev., 34, 550 (1984).

4. R. J. Loprest and E. F. McInerney, U.S. Patent 4093461 (1978).

5. H. Simmons, U.S. Patent 5399655 (1995).
6. K. Sakayori, Y. Shibasaki, and M. Ueda, Polym. J., 38, 1189 (2006)

7. R. Rubner, A. Hammerschmidt, R. Leuschner, and H. Ahne, in "Polymer Microelectronics: Proceeding of the International Symposium,” Y. Tabata, Ed., Kodansha, Tokyo, 1990, p 789.

8. K. Yamamoto and T. Hirano, J. Photopolym. Sci. Technol., 15, 173 (2002).

9. Y. Watanabe, Y. Shibasaki, S. Ando, and M. Ueda, Polym. J., 37, 270 (2005).

10. S. Kubota, T. Moriwaki, T. Ando, and S. Fukami, J. Appl. Polym. Sci., 33, 1763 (1987).

11. T. Omote, K. Koseki, and T. Yamaoka, Macromolecules, 23, 4788 (1990).

12. T. Okabe, T. Miwa, T. Ueno, S. Yamada, and M. Nunomura, Jpn Kokai, Tokkyo Koho, 2000-221667 (2000).

13. S. Yoshida, M. Eguchi, K. Tamura, and M. Tomikawa, J. Photopolym. Sci. Technol., 20, 145-7 (2007).

14. S. Sugawara, M. Tomoi, and T. Oyama, Polym. J., 39, 129 (2007).

15. K. Fukukawa and M. Ueda, Polym. J., 40, 281 (2008).

16. M. L. Sherrill, F. L. Schaeffer, and E. P. Shoyer, J. Am. Chem. Soc., 50, 474 (1928).

17. A. Mochizuki, T. Teranishi, and M. Ueda, Polym. J., 26, 315 (1994).

18. H. Meerwein, F. Burner, O. Fuchs, H. J. Sasse, H. Schordt, and J. Spille, Chem. Ber., 89, 2060 (1956).

19. R. F. Abdulla and R. S. Brinkmeyer, Tetrahedron, 35, 1675 (1979).

20. U. Meierhenrich, W. H.-P. Thiermann, and H. Rosenbauer, J. Anal. Appl. Pyrolysis, 60, 13 (2001).

21. K. H. Yu, Y. H. Yoo, J. M. Rhee, M.-H. Lee, and S.-C. Yoo, Mater. Res. Innovations, 7, 51 (2003).

22. S. M. Choi, S.-H. Kwon, and M. H. Yi, J. Appl. Polym. Sci., 100, 2252 (2006).

23. K. Kato, M. Hashimoto, and Y. Hashimoto, Jpn Kokai, Tokkyo Koho, 1999-38611 (1999). 